\title{
Détection d'Erwinia chrysanthemi pv dianthicola par le test Elisa après enrichissement bactérien
}

\author{
A Nassar, JP Narcy, M Lemattre * \\ Unité de pathologie végétale, Inra, route de Saint-Cyr, F-78026 Versailles, France
}

(Reçu le 9 mars 1995; accepté le 2 février 1996)

\begin{abstract}
Résumé - L'indexage des boutures d'œillet vis-à-vis d'Erwinia chrysanthemi pv dianthicola (Ech) repose sur l'établissement d'un diagnostic fiable de la bactérie, en particulier dans les organes sans symptôme, faiblement infectés. La méthode Elisa mieux adaptée au traitement d'échantillons nombreux a été choisie. Avec le sérum polyclonal dont la spécificité est évaluée dans cet article, cette méthode permet d'identifier $5 \times 10^{3}$ bactéries. $\mathrm{mL}^{-1}$. Différentes conditions d'incubation de l'échantillon à analyser en Das-Elisa sont étudiées de manière à multiplier Ech pour l'amener à une concentration supérieure à celle du seuil de détection établi. Les milieux LB et CVP permettent de multiplier rapidement la bactérie mais diminuent l'accrochage bactérie-anticorps au cours de la détection immunoenzymatique. L'incubation de l'échantillon dans l'eau physiologique à $30^{\circ} \mathrm{C}$ permet, sans intervenir sur l'accrochage bactérie-anticorps, d'amplifier l'inoculum primaire. Le protocole d'analyse associant l'enrichissement et la technique Das-Elisa et son exploitation à grande échelle sont discutés sur le plan technique.
\end{abstract}

Erwinia chrysanthemi pv dianthicola / œillet / enrichissement / Das-Elisa

Summary - Detection of Erwinia chrysanthemi pv dianthicola (Ech) by the DAS-ELISA method in symptomless carnation cuttings. This method, using a polyclonal antiserum, the specificity of which was evaluated in this study, can detect up to $5 \times 10^{3} \mathrm{cfu} . \mathrm{mL}^{-1}$. Different incubation conditions of carnation stem samples to be tested by DAS-ELISA were studied, in order to amplify the primary inoculum in weakly-infected symptomless samples. The aim was to increase the detection limits. The media $L B$ and CVP, which ensure enrichment of Ech in samples, interfere with efficient antigen-antibody interaction. By contrast, incubation of samples in saline at $30{ }^{\circ} \mathrm{C}$ allows amplification without loss of antibody recognition. The exploitation of this method for routine analysis of carnation stem samples is discussed.

E chrysanthemi pv dianthicola / carnation / enrichment / DAS-ELISA

\section{INTRODUCTION}

Le flétrissement et le nanisme bactérien (Erwinia chrysanthemi pv dianthicola) de l'œillet (Dianthus caryophyllus L) décrit en Europe (Lelliott, 1956;
Hellmers, 1958; Bakker et Scholten, 1961; Bonnet, 1970), aux États-Unis (Dimock, 1958) et en Nouvelle-Zélande (Boesewinkell, 1973) est actuellement en recrudescence dans le bassin méditerranéen (Lercari, communication personnelle).

\footnotetext{
* Correspondance et tirés à part
} 
La bactérie est transmise par le sol et par le matériel végétal de propagation (Mercier et al, 1967). Le polymorphisme du pv dianthicola, décrit par Boccara et al (1991) et Nassar et al (1994), est lié à l'origine géographique et à l'hôte.

Pour certifier les plants indemnes de cette bactérie, il convient de disposer d'une méthode sensible, fiable et rapide, de préférence automatisable, permettant de détecter et d'identifier spécifiquement l'organisme pathogène.

La méthode Elisa (Enzyme-linked immunosorbent assay) (Avrameas et Guilbert, 1971), répondant à ces exigences et déjà pratiquée pour l'indexage des boutures d'œillet vis-à-vis des virus (Devergne et al, 1982), a été considérée comme insuffisamment sensible pour la détection des bactéries dans les échantillons (Van Vuurde, 1987) et en particulier dans les tissus d'œillet infectés par $E$ chrysanthemi pv dianthicola (Muratore et al, 1986), le seuil de détection se situant autour de $9 \times 10^{4}$ bactéries. $\mathrm{mL}^{-1}$. Avec les variantes Das-Elisa (Double antibody sandwich-ELISA) et Ba Das-Elisa (Biotine-avidine DAS-ELISA) en présence de tiges de dahlia, Goumas et al (1986) atteignent des seuils de détection d'E chrysanthemi proches de $10^{3}$ bactéries. $\mathrm{mL}^{-1}$.

Pour détecter les échantillons faiblement infectés, non identifiés en Das-Elisa, Philippot et al (1990) proposent, dans le cas de Xanthomonas campestris pv begoniae, d'incuber préalablement l'échantillon végétal à analyser dans un milieu d'enrichissement. Bien que ce milieu joue un rôle dans l'accrochage de l'antigène sur l'anticorps, la détection de $X$ campestris pv begoniae s'en trouve nettement améliorée.

Le présent travail a pour objet la mise au point et l'évaluation de la méthode Das-Elisa après multiplication de l'inoculum primaire de l'échantillon à analyser sur un milieu adapté.

\section{MATÉRIEL ET MÉTHODE}

\section{Souches bactériennes}

Deux souches d'E chrysanthemi pv dianthicola (2021 et 1151), d'origines géographiques différentes, appartenant au groupe 1 (Nassar et al, 1994) et une souche (30121) isolée d'œillet, mais hors de ce groupe, ont été utilisées pour les immunisations. Les souches bactériennes pathogènes et les souches saprophytes isolées de l'œillet (tableau I) ont servi à établir la spécificité de l'immun-sérum 2021.

\section{Production des immun-sérums et purification des $\lg G$}

L'immunisation réalisée avec des bactéries tuées par la chaleur donne des sérums de titre supérieur à celle réalisée avec des bactéries vivantes (Tsuchiya et al, 1991). Les bactéries ont donc été cultivées 24 heures à $30{ }^{\circ} \mathrm{C}$ sur milieu LB (Luria Bertani, Bacto-Tryptone $10 \mathrm{~g}$, extrait de levure $5 \mathrm{~g}, \mathrm{NaCl} 10 \mathrm{~g}, \mathrm{H}_{2} \mathrm{O} 1000 \mathrm{~mL}$ ), lavées trois fois par centrifugation, mises en suspension dans l'eau physiologique $(0,85 \%$ de $\mathrm{NaCl})$ à la concentration de $10^{9}$ bactéries. $\mathrm{mL}^{-1}$ et inactivées par ébullition pendant 2 heures.

Les immunisations sont réalisées avec la suspension bactérienne seule pour les injections intraveineuses (IV) et mélangée à volume égal avec l'adjuvant incomplet de Freund pour les injections sous-cutanées (SC) (Lamka et al, 1991) (fig 1).

La détermination du titre en anticorps de ces trois immun-sérums est estimée par ACP-Elisa (Antigen coated plate-ELISA) (Vollera et al, 1976), avec utilisation d'un conjugué anti-IgG de lapin (Biosys, France) à la dose prescrite. Les dilutions sont effectuées dans le tampon PBS-T (Phosphate buffered saline avec 0,5\% de Tween 20).

En Das-Elisa, après purification des immunoglobulines groupe $G$ ( $\operatorname{lgG}$ ) par chromatographie d'affinité sur sepharose-protéine $A$ et couplage à la phosphatase

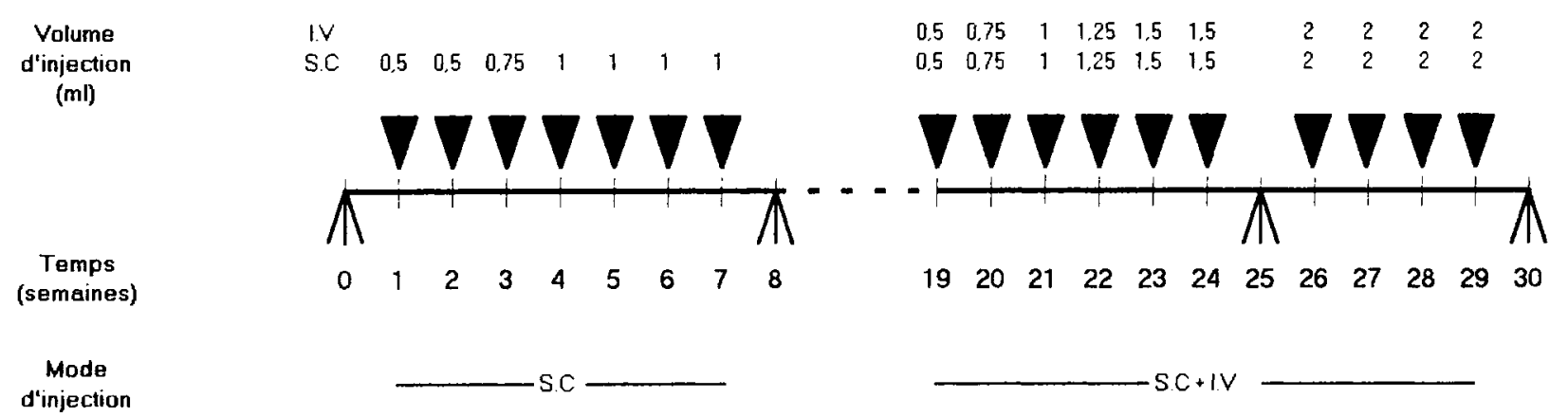

Fig 1. Schéma d'immunisation des lapins avec les souches d'E chrysanthemi $(1151,2021,30121)$. SC = injections sous-cutanées, IV $=$ injections intraveineuses, $\boldsymbol{\nabla}=$ injection, $\mathbb{\Lambda}=$ prélèvement. 
alcaline selon Gorthier et al (1984), la concentration d'antigène minimale détectée (seuil de sensibilité) est obtenue avec une concentration en $\operatorname{lgG}$ de première couche de $0,25 \mu \mathrm{g} \cdot \mathrm{mL}^{-1}$ et une dilution du conjugué au 1/8 000. L'activité enzymatique est mesurée par l'absorbance (DO) à $405 \mathrm{~nm}$ au spectrophotomètre (Molecular Device). Chaque valeur correspond à la moyenne de trois répétitions.

Les tests sont effectués sur plaques de microtitration Greiner avec des dépôts de $200 \mu \mathrm{L}$ par puits pour chaque étape. Les puits sont rincés avec du PBS-T entre les incubations.

\section{Préparation des échantillons}

\section{Inoculation du matériel végétal}

Des boutures non racinées d'œillet cv Kaly sont inoculées avant plantation par trempage dans une suspension bactérienne des souches 2021 et 30121 à la concentration de $10^{6}$ bactéries. $\mathrm{mL}^{-1}$ en eau physiologique pendant 16 heures. Les témoins sont traités à l'eau physiologique.

\section{Dispositif expérimental}

Deux milieux d'enrichissement liquides sont utilisés pour l'incubation des prélèvements végétaux : le milieu complet LB et le milieu sélectif CVP (Crystal Violet Pectate, Cuppels et Kelman, 1974) qui privilégie la croissance des bactéries pectinolytiques à Gramnégatif. À ces milieux sont incorporés :
- soit l'inoculum calibré évalué par spectrophotométrie et confirmé par comptage (souches 2021 et 30121), avec et sans fragments de tige d'œillets sains ;

- soit des fragments de tige de plantes artificiellement infectées, âgées de deux mois et ne présentant pas de symptômes, prélevées deux mois après plantation, à $1 \mathrm{~cm}$ de la zone d'enracinement.

Les tiges désinfectées extérieurement, puis coupées en sections de 1 ou $5 \mathrm{~mm}$, sont ensuite incubées à 4 et $30^{\circ} \mathrm{C}$ pendant 16 heures dans les milieux LB, CVP ou l'eau physiologique considérée comme témoin. Le rapport, poids de l'échantillon sur volume du milieu, est de 1/5. Après incubation, le liquide dans lequel les bactéries ont diffusé est mélangé volume à volume au tampon PBS-T concentré deux fois.

\section{RÉSULTATS}

Les résultats portent sur quatre points :

\section{Titre des trois immun-sérums obtenus}

À la concentration de $10^{4}$ bactéries. $\mathrm{mL}^{-1}$, le titre des différents immun-sérums se situe à $10^{-5}$ en Acp-Elisa. Avec les sérums témoin (avant immunisation) et aux mêmes concentrations, aucune réaction positive n'est apparue. L'immun-sérum anti-2021 est le plus riche en anticorps (fig 2).
Fig 2. Comparaison en Acp-Elisa du prélèvement à la $30^{\mathrm{e}}$ semaine des trois immuns sérums d'E chrysanthemi. Temps de réaction enzymatique : 1 heure. Antigènes utilisés à la concentration de $10^{4}$ bactéries. $\mathrm{mL}^{-1}$. - $\mathbf{A}$ - sérum anti1151, —*- sérum anti-30121, - - sérum anti-2021.
Absorbance $(405 \mathrm{~nm})$

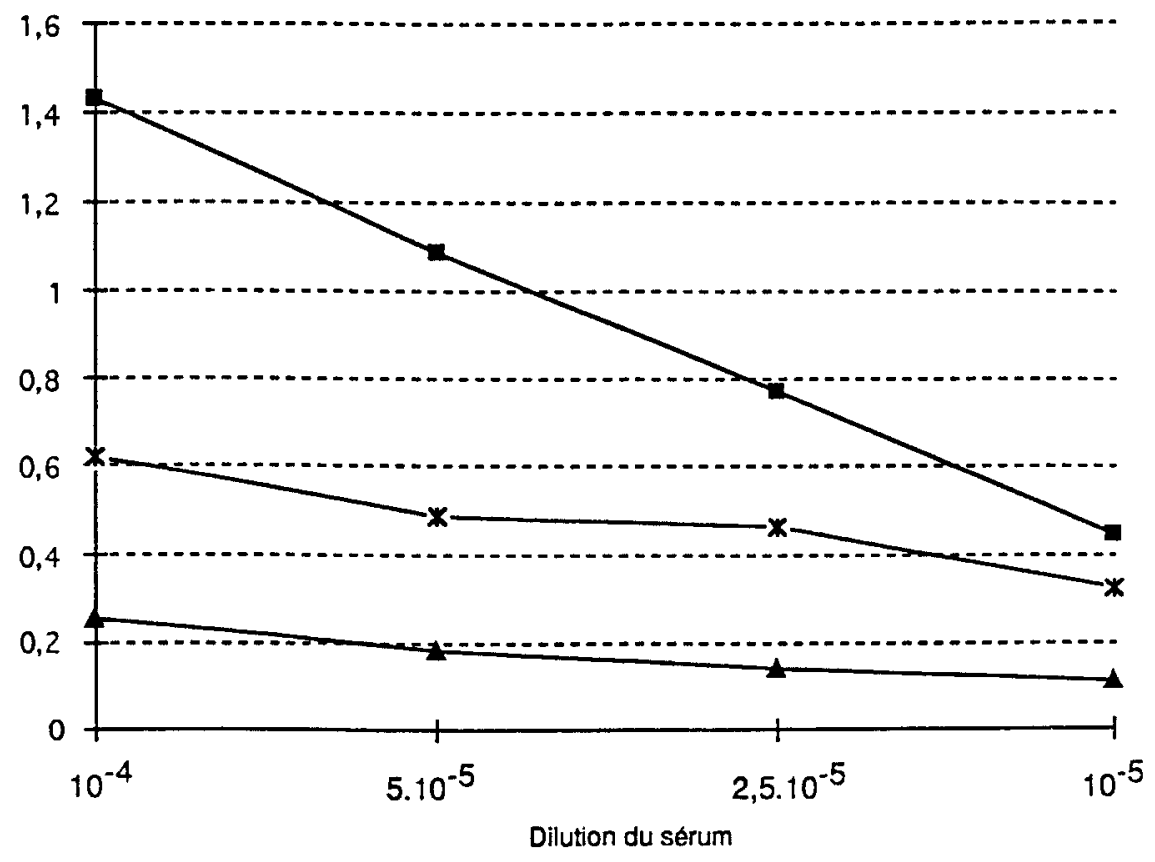


Tableau I. Spécificité du sérum anti-2021 en Das-Elisa.

Souche

Plante hôte

SF18-538

3263

3265

3266

2048

1242

1529

3367

2013

30332

3642

1237

1345

3716

2598

1443

1272

2711

1888

2288

Cip 366

2268

30920

722

ET 11

E carotovora carotovora

40329

40990

E carotovora atroseptica

40501

40884
CEillet

Endive

Banane
CEillet
Endive
Kalanchoë
Anangonium
Pomme de terre
Chrysanthème
Maïs
Dahlia
Dieffenbachia

Saintpaulia

Tomate

Cyclamen

Primevère

Pomme de terre Endive

France, 1982

France, 1973

France, 1972

France, 1972

France, 1965

France, 1972

Italie, 1967

Italie

Italie

Italie

Italie

États-Unis

France, 1981

Suisse

France, 1982

France, 1983

France, 1983

États-Unis

États-Unis

France, 1977

France, 1974

France, 1977

France, 1974

Italie, 1969

France, 1978

Suisse, 1982

Malaisie, 1961

Australie

France, 1978

France, 1980

Pérou

France, 1977

France, 1965

France, 1984

France, 1982

Pois
Origine géographique Source a Réponse en et année d'isolement Das-Elisa

Côte-d'Ivoire, 1976

Colombie, 1972

Colombie, 1972

Danemark, 1956

Danemark, 1957

Royaume-Uni, 1956

Royaume-Uni, 1956

États-Unis, 1956

Allemagne, 1962

États-Unis, 1972

Australie, 1978

Martinique, 1988

3

3

3

1

Haricot 
Tableau I. Cont.

Souche

Plante hôte

Origine géographique et année d'isolement

Source a Réponse en Das-Elisa

Pseudomonas syringae pv syringae 1147

Poirier

France, 1965

Pseudomonas caryophylli 2429

aillet

États-Unis

Pseudomonas fluorescens 2102

2125

Eau

Royaume-Uni, 1951

Pseudomonas corrugata 2431

Tomate

Royaume-Uni

Xanthomonas campestris pv campestris 528

Xanthomonas campestris pv phaseoli 1816

Haricot

1

Xanthomonas campestris pv oryzicola 2286

Riz

Malaisie, 1964

Canne à sucre

Guadeloupe

5

15003

Fraisier

États-Unis, 1966

7 2473

France

3

Agrobacterium tumefaciens 60101

3

a Code des sources de culture : 1 = Collection française de bactéries phytopathogènes (CFBP), Inra, Angers, France ; $2=\mathrm{R}$ Samson, Inra, Angers, France ; 3 = M Lemattre, Inra, Versailles, France ; 4 = Culture Collection Plant Pathogenic Service, Wageningen, PaysBas ; 5 = Irat-Cirad, Martinique, France ; 6 = B Jouan, Inra, Rennes, France ; $7=$ NCPPB, National Collection of Plant Pathogenic Bacteria, Harpenden, Royaume-Uni. b Souches utilisées en immunisation.

\section{Spécificité de l'immun-sérum anti-2021}

L'immun-sérum anti-2021 ne reconnaît aucune des souches appartenant aux espèces et genres autres qu'E chrysanthemi, notamment Pseudomonas caryophylli, bactérie pathogène de l'œillet, de même qu'aucune des 28 souches de la flore épiphyte isolée d'œillet.

Toutes les souches d'E chrysanthemi sont reconnues, exceptées celles isolées de banane, ananas et deux souches isolées de pomme de terre, qui diffèrent par leurs profils ARNr et PCRRFLP (Nassar et al, 1994).

Toutes les souches isolées d'œillet sont identifiées. Ces résultats sont présentés au tableau I.

\section{Sensibilité du test Das-Elisa}

Le seuil de sensibilité évalué sur suspension bactérienne étalonnée se situe à $5 \times 10^{3}$ bactéries. $\mathrm{mL}^{-1}$ dans le tampon PBS-T avec et sans fragments de tige d'œillet (fig 3 ).

\section{Intérêt et limite de l'enrichissement}

\section{Enrichissement obtenu sur les milieux LB et CVP}

Après 16 heures d'incubation à $30^{\circ} \mathrm{C}$, l'accroissement de l'inoculum primaire $\left(10^{4}\right.$ 
Tableau II. Taux d'enrichissement de l'inoculum primaire (B), sur deux milieux, LB et CVP, à $30^{\circ} \mathrm{C}$ en présence d'échantillons végétaux (EV). Témoin eau physiologique $\left(\mathrm{H}_{2} \mathrm{O}\right)$ à $4{ }^{\circ} \mathrm{C}$.

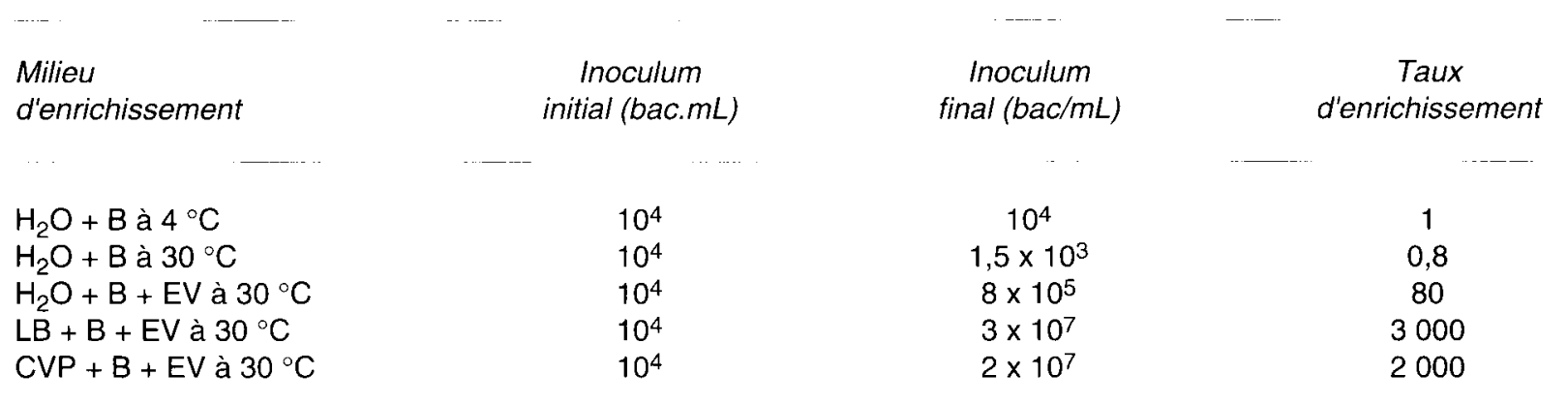

Dénombrement des bactéries par dilutions-étalements (moyenne de trois répétitions).

bactéries. $\mathrm{mL}^{-1}$ ), dans les deux milieux de culture et l'eau physiologique, additionnés de fragments végétaux est évalué par comptages après étalement sur milieu gélosé (tableau II).

Ils montrent que l'enrichissement de la population bactérienne initiale dans le milieu LB est supérieur à celui obtenu dans le milieu CVP. En eau physiologique, à $30^{\circ} \mathrm{C}$ comme à $4{ }^{\circ} \mathrm{C}$, l'accroissement de l'inoculum en l'absence de tissus végétaux est nul, en revanche, à $30^{\circ} \mathrm{C}$, la bactérie se multiplie lorsque les fragments de plante hôte sont présents.

\section{Influence de la composition du milieu sur l'accrochage bactérie-anticorps}

En conditions de température défavorables à la multiplication bactérienne $\left(4{ }^{\circ} \mathrm{C}\right)$, après
16 heures d'incubation des bactéries en présence des tissus d'œillet, on constate que les métabolites diffusés par ces derniers jouent un rôle dépressif sur l'accrochage bactérie-anticorps (séries 1 et 2) (fig 4). Cet effet diminue avec la dilution du liquide de diffusion (série 2).

En conditions d'incubation favorables à la multiplication des bactéries $\left(30^{\circ} \mathrm{C}\right)$, l'effet négatif des métabolites d'origine végétale ou bactérienne sur l'accrochage bactérie-anticorps est confirmé (série 3).

Si l'on compare les séries 3, 4 et 6, il apparaît que c'est après incubation dans le milieu CVP que l'accrochage est le plus faible, alors qu'il se situe au même niveau dans le milieu LB et l'eau physiologique. L'effet s'atténue là aussi après dilution du liquide de diffusion.

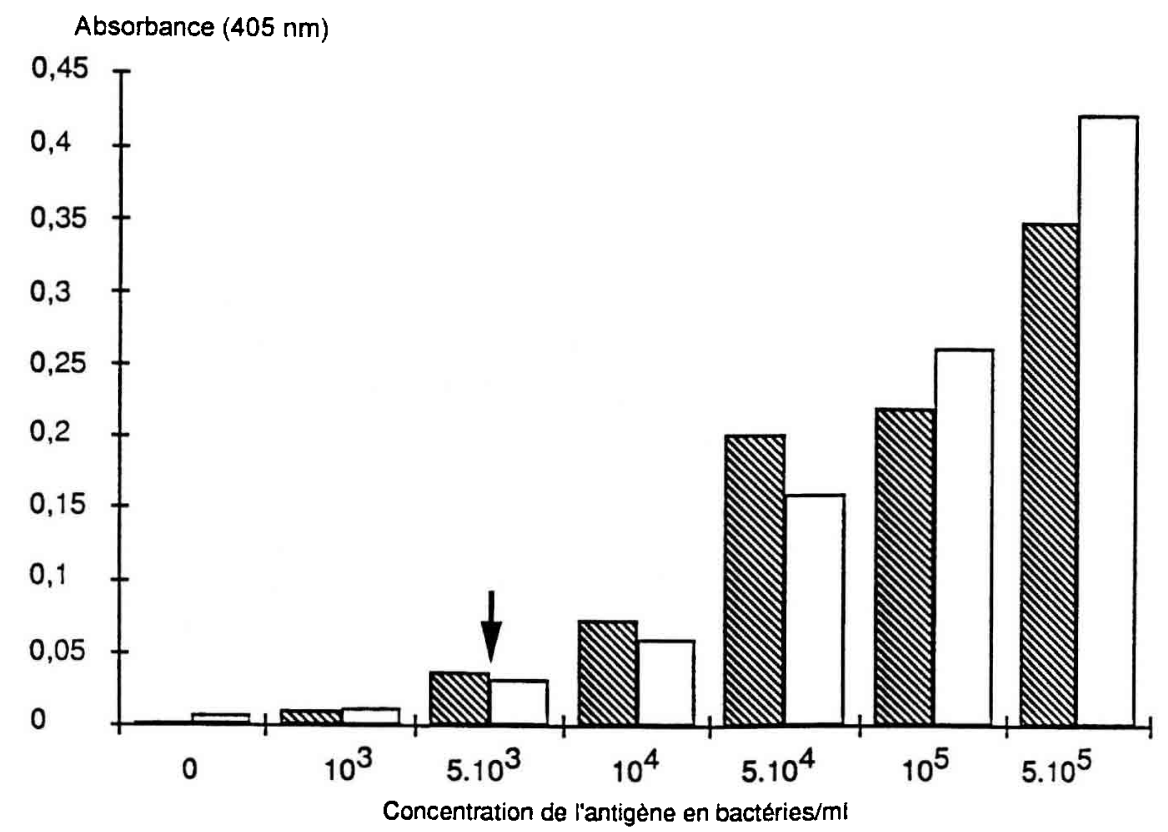

Fig 3. Limite de détection d'E chrysanthemi (souche 2021) en DasElisa en présence et en absence d'échantillon végétal. Sérum anti2021; temps de réaction enzymatique : 1 heure. $\mathbb{N}=$ suspension bactérienne calibrée dans le PBS$\mathbf{T} ; \square=$ bactéries incorporées dans le PBS-T en présence d'échantillons végétaux incubés 16 heures à $4{ }^{\circ} \mathrm{C} ; \downarrow=$ seuil de détection. 


\section{Détection sur plantes infectées artificiellement}

L'incubation 16 heures à $30^{\circ} \mathrm{C}$ dans l'eau physiologique des fragments de tige de plantes de 2 mois issues des boutures infectées avant bouturage permet une augmentation sensible de la population bactérienne initiale (fig 5). Les valeurs d'absorbance des liquides de diffusion témoin, maintenus à $4{ }^{\circ} \mathrm{C}$, sont sensiblement égales à celles des dilutions au 1/100 de ceux incubés à $30{ }^{\circ} \mathrm{C}$. Autrement dit, à la température optimale de croissance, l'inoculum initial est multiplié par 100 sans autres sources nutritionnelles que celles des tissus de l'œillet.

\section{DISCUSSION}

L'immun-sérum utilisé au cours de ce travail permet d'identifier les souches d'Ech pathogènes de l'œillet, qu'elles appartiennent ou non au pv dianthicola.

Les données présentées montrent l'intérêt d'une incubation préalable des fragments de tige à analyser (fig 5), de manière à permettre à l'inoculum bactérien initial des plantes de diffuser hors des tissus et de se multiplier dans la phase liquide pour atteindre le seuil de détection en Das-Elisa. L'incubation en eau physiologique permet d'assurer l'identification d'inoculums très faibles situés en dessous du seuil de détection en Das-Elisa $\left(5 \times 10^{3}\right.$ bactéries. $\left.\mathrm{mL}^{-1}\right)$. Bien que l'enrichissement soit plus important avec le milieu complet (LB) et le milieu sélectif des germes pec- tinolytiques (CVP), les inconvénients introduits par leur utilisation au niveau de l'accrochage bactérie-anticorps limitent pourtant leur intérêt par rapport à l'eau physiologique.

Le milieu CVP, reconnu pour sa sélectivité dans des études de population d'E carotovora (Pérombelon et Kelman, 1980), permet une croissance légèrement moindre d'E chrysanthemi que le milieu non sélectif LB ; en revanche, il limite davantage la croissance des germes saprophytes (Pérombelon et Hyman, 1986). Toutefois ces germes qui ne sont pas reconnus par l'immun-sérum utilisé ne devraient pas avoir d'incidence sur l'interprétation des résultats en Elisa. En outre, dans le protocole choisi, la flore saprophyte polluante a été éliminée par la désinfection préalable du fragment végétal, ce qui explique son absence ou sa très faible présence sur les ensemencements réalisés. Par ailleurs, le choix de plantes cultivées en serre sur substrats inertes et de stades précoces d'infection contribuent à limiter l'expression de la flore bactérienne. La présence de ces germes qui pourraient limiter la croissance des souches d'Ech n'a pas été confirmée sur les prélèvements effectués après incubation de l'échantillon lors du comptage des colonies bactériennes.

Si l'on compare l'incidence de la composition du milieu, en particulier celle du témoin eau physiologique sur l'accrochage bactérie-anticorps, le choix du milieu d'incubation doit être reconsidéré au profit d'une phase liquide simple (eau physiologique), puisque la bactérie peut se multiplier en puisant les sources nutritionnelles nécessaires à
Fig 4. Effet du milieu d'enrichissement sur l'accrochage des bactéries (souche 2021) en Das-Elisa. Sérum anti-2021; temps de réaction enzymatique : 30 minutes. Bactéries (AG) apportées à la concentration finale de $10^{6}$ bactéries. $\mathrm{mL}^{-1}$. $1 \mathrm{AG}$ en eau physiologique 16 heures à $4{ }^{\circ} \mathrm{C} ; 2$ $A G$ en eau physiologique 16 heures à $4{ }^{\circ} \mathrm{C}$ et en présence d'échantillons végétaux ; $3 \mathrm{AG}$ en eau physiologique incubé 16 heures à $30^{\circ} \mathrm{C}$ en présence d'échantillons végétaux ; 4 $A G$ en milieu LB incubé 16 heures à $30{ }^{\circ} \mathrm{C}$ en présence d'échantillons végétaux ; $5 \mathrm{AG}$ dans les conditions précédentes mais lavés par centrifugation pour éliminer le milieu ; 6 AG en milieu CVP incubé 16 heures à $30{ }^{\circ} \mathrm{C}$ en présence d'échantillons végétaux.

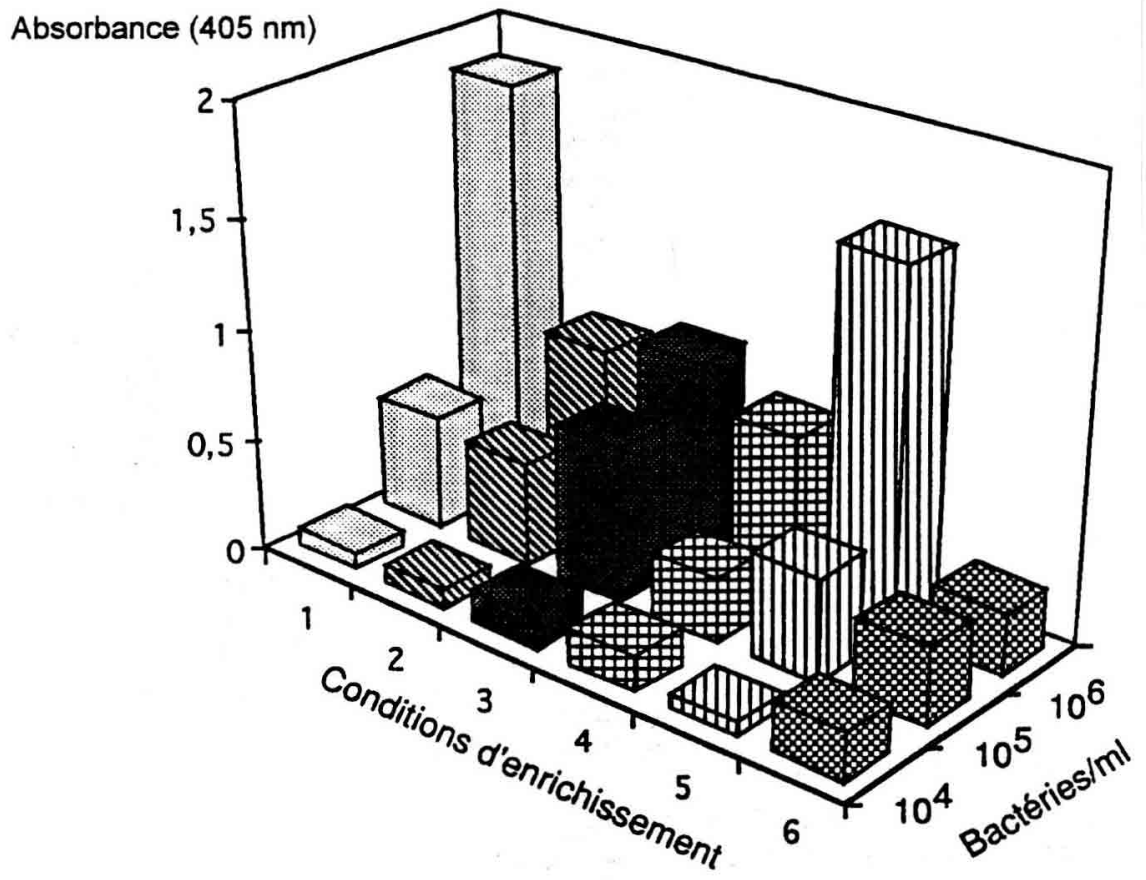


Absorbance $(405 \mathrm{~nm})$

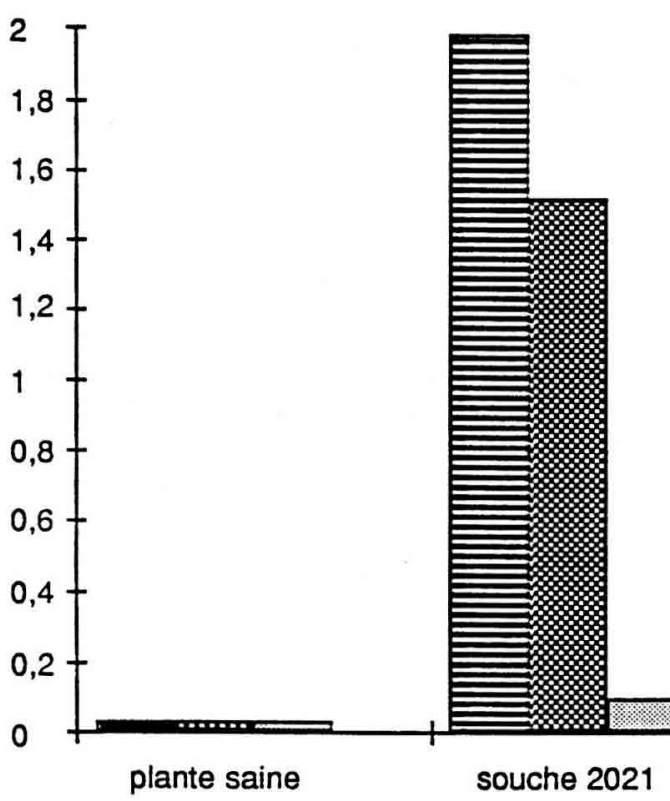

sa croissance à partir des fragments végétaux. II serait intéressant, pour l'analyse d'échantillons présentant des symptômes, d'évaluer l'incidence des métabolites diffusés lorsque les tissus sont fortement dégradés. En revanche, pour le contrôle sanitaire des organes de multiplication, choisis sur des plantes d'apparence saine, cette éventualité peut être écartée.

Le choix de fragments résulte d'observations antérieures, montrant que la dilacération ou le broyage de l'échantillon accroissent le bruit de fond en Elisa. Ce procédé réduit en outre le temps de préparation et donc le coût de l'opération.

Les résultats présentés devront être validés sur du matériel naturellement infecté. Cependant, la maladie n'étant jamais généralisée, tous les organes d'un pied mère infecté ne sont pas systématiquement colonisés. Ce matériel paraît donc mal approprié pour conclure sur la présence ou l'absence de la bactérie dans le pied mère.

\section{RÉFÉRENCES}

Avrameas S, Guilbert B (1971) Dosage enzymo-immunologique des protéines à l'aide d'immunoadsorbants et d'antigènes marqués aux enzymes. $C R$ Acad Sci Ser D 273, 2705-2707

Bakker M, Scholten G (1961) Bacteri-eziekten bij Amerikaanse Anjers in Nederland. Tijdschr Plantenziekten 67, 296-302

Boccara M, Vedel R, Lalo D, Lebrun MH, Lafay JF (1991) Genetic diversity and host range in strains of
Fig 5. Détection en Das-Elisa d'E chrysanthemi (souches 2021 et 30121 ) sur plantes malades macérées 16 heures dans l'eau physiologique. Sérum anti-2021; temps de réaction enzymatique : 2 heures. Macération de tiges sains à $30^{\circ} \mathrm{C}$; a macération de tiges infectées sans symptôme à $4^{\circ} \mathrm{C}$ (témoin), macération de tiges infectées sans symptôme à $30^{\circ} \mathrm{C}$; diluée au $1.10^{-2}$; dilué au $1.10^{-3}$.
Erwinia chrysanthemi. Mol Plant-Microbe Interact 4, 293-299

Boesewinkel HJ (1973) Bacterial wilt of carnation in New Zealand. Plant Dis Rep 57, 136-140

Bonnet $P$ (1970) Étude comparée des caractères biochimiques du Pectobacterium parthenii (Starr) Hell var Dianthicola (Hell) et de différentes souches de Pectobacterium, d'Aerobacter et de Serratia. Ann Phytopathol 2, 209-225

Cuppels D, Kelman A (1974) Evaluation of selective media for isolation of soft-rot bacteria from soil and plant tissue. Phytopathology 64, 468-475

Devergne JC, Cardin L, Bontemps J (1982) Indexages biologique et immunoenzymatique (Elisa) pour la production d'œillets indemnes de virus de la marbrure (CarMV). agronomie 2, 655-666

Dimock AW (1958) Reports on carnation disease. Carnation Craft 43, 1-5

Gorthier G, Boschetti E, Charley-Poulain J (1984) Improved method for IgG purification from various animals species by ion-exchange chromatography. $J$ Immunol Methods 66, 75-79

Goumas D, Lemattre M, Narcy JP, Albouy J, Larroque $N$ (1986) Detection of bacteria and virus in dahlia by immuno-enzymatic tests. Acta Horticult 177, 115-120

Hellmers E (1958) Four wilt diseases of perpetual flowering carnation in Denmark. Danak Botan Arkiv $18,1-200$

Lamka GL, Hill JH, McGee DC, Braun EJ (1991) Development of an immunosorbent assay for seedborne Erwinia stewartii in corn seeds. Phytopathology 81, 839-846

Lelliott RA (1956) Slow wilt or carnations caused by a species of Erwinia. Plant Patho/ 56, 19-23

Mercier S, Pionnat JC, Tramier R (1967) Recherches sur le flétrissement bactérien de l'œillet dû au 
Pectobacterium parthenii var dianthicola (Hellmers). Phytiatr Phytopharm 16, 149-156

Muratore MG, Mazzucchi U, Gasperini C, Fiori M (1986) Detection of latent infection of Erwinia chrysanthemi and Pseudomonas caryophylli in carnation. Bull OEPP 16, 1-12

Nassar A, Bertheau Y, Dervin C, Narcy JP, Lemattre M (1994) Ribotyping of Erwinia chrysanthemi strains in relation to their pathogenic and geographic distribution. Appl Environ Microbiol 60, 3781-3789

Perombelon MCM, Kelman A (1980) Ecology of the soft rot erwinias. Annu Rev Phytopathol 18, 361-387

Perombelon MCM, Hyman LJ (1986) A rapid method for identifying and quantifying soft rot erwinias directly from plant material based on their temperature tolerances and sensitivity to erythromycin. J Appl Bacteriol 60, 61-66
Philippot P, Narcy JP, Berthier Y, Lemattre M (1990) Mise au point d'un test immunoenzymatique pour la détection de Xanthomonas campestris pv begoniae. In : $2^{e}$ Congrès SFP, Montpellier, $1 \mathrm{p}$

Tsuchiya K, Takahashi Y, Shohara K, Homma Y, Suzui T (1991) Rapid and simple ELISA procedure for the specific detection of Pseudomonas cepacia in soil. Ann Phytopathol Soc Jpn 57, 196-202

Van Vurde JWL (1987) New approach in detecting phytopathogenic bacteria by combined immunoisolation and immunoidentification assays. Bull OEPP $17,139-148$

Vollera A, Bidwell DE, Bartlett A (1976) Microplate enzyme immuno assays for the immuno diagnosis of virus infections. Manual of Clin Immuno. ASM, Washington, DC, 506-512 